\title{
Development of Hydrotalcite Based Cobalt Catalyst by Hydrothermal and Co-precipitation Method for Fischer- Tropsch Synthesis
}

\author{
M. Faizan Sharif ${ }^{1}$, Muhammad Arslan $^{1}$, Naseem Iqbal ${ }^{1 *}$, Nisar Ahmad ${ }^{2}$, Tayyaba Noor ${ }^{3}$ \\ ${ }^{1}$ US Pakistan Centre for Advanced Studies in Energy (USPCAS-E), National University of Sciences \\ and Technology, Islamabad 44000, Pakistan \\ ${ }^{2}$ National Centre for Physics (NCP), Islamabad 44000, Pakistan \\ ${ }^{3}$ School of Chemical and Materials Engineering (SCME), National University of Sciences and \\ Technology, Islamabad 44000, Pakistan
}

Received: $3^{\text {rd }}$ November 2016; Revised: $26^{\text {th }}$ February 2017; Accepted: $9^{\text {th }}$ March 2017;

Available online: 27th October 2017; Published regularly: December 2017

Abstract

This paper presents the effect of a synthesis method for cobalt catalyst supported on hydrotalcite material for Fischer-Tropsch synthesis. The hydrotalcite supported cobalt (HT-Co) catalysts were synthesized by co-precipitation and hydrothermal method. The prepared catalysts were characterized by using various techniques like BET (Brunauer-Emmett-Teller), SEM (Scanning Electron Microscopy), TGA (Thermal Gravimetric Analysis), XRD (X-ray diffraction spectroscopy), and FTIR (Fourier Transform Infrared Spectroscopy). Fixed bed micro reactor was used to test the catalytic activity of prepared catalysts. The catalytic testing results demonstrated the performance of hydrotalcite based cobalt catalyst in Fischer-Tropsch synthesis with high selectivity for liquid products. The effect of synthesis method on the activity and selectivity of catalyst was also discussed. Copyright (c) 2017 BCREC Group. All rights reserved

Keywords: Fischer-Tropsch synthesis; Cobalt catalyst; Hydrotalcite; Co-precipitation; Hydrothermal

How to Cite: Sharif, M.S., Arslan, M., Iqbal, N., Ahmad, N., Noor, T. (2017). Development of Hydrotalcite Based Cobalt Catalyst by Hydrothermal and Co-precipitation Method for Fischer-Tropsch Synthesis. Bulletin of Chemical Reaction Engineering \& Catalysis, 12(3): 357-363

(doi:10.9767/bcrec.12.3.762.357-363)

Permalink/DOI: https://doi.org/10.9767/bcrec.12.3.762.357-363

\section{Introduction}

The rising awareness about using clean fuels and increasing inclination of masses towards green economies is influencing the oil industry to a great extent. There is more effort in play to minimize the environmental impacts of fuel in use. Work is being done to find a sustainable option that can both meet ever rising energy de-

* Corresponding Author.

E-mail: naseem@casen.nust.edu.pk (Iqbal, N.)

Telp.: +92-51-90855281 mand as well as reduces environmental impacts of fuel. Fischer-Tropsch synthesis is one of the cleaner production techniques and is used for generation of liquid products that are comparatively less hazardous to the environment as compared to their precursor [1]. Fischer-Tropsch synthesis (FTS) is a commercial polymerization process used for conversion of hydrogen and carbon monoxide into a variety of sulfur and aromatics-free hydrocarbons having wide range of chain length and functionality [2]. Syngas, which is a mixture of hydrogen and carbon monoxide, can be prepared by the gasification of coal 
or biomass and steam reforming of methane $[3,4]$.

The FTS process usually employs a catalyst to carry out the reaction. Apart from others, iron and cobalt are the most commonly used active component of the catalysts used for FTS [5]. Heavy paraffin and light olefins are the characteristic product of cobalt catalysts whereas iron catalysts are inclined towards producing oxygenated compounds and branched hydrocarbons [6]. Iron catalysts can operate at a wide range of pressure, temperature, and $\mathrm{H}_{2} / \mathrm{CO}$ ratio on the other hand cobalt catalysts can operate at limited temperatures, $\mathrm{H}_{2} / \mathrm{CO}$ ratios and pressures [7]. Cobalt catalyst is more stable, more active, and has high selectivity towards straight chain hydrocarbons that is why cobalt is preferred in case of the higher $\mathrm{H}_{2} / \mathrm{CO}$ ratio of syngas.

There are several types of support materials which can be used in Fischer-Tropsch catalysis. The choice of support material has an enormous effect on the activity and efficiency of catalyst [6]. Hydrotalcites are hydroxides having manifold layered structure and have the potential to be utilized as support material for catalyst in Fischer-Tropsch synthesis, and are widely used as a support material for cobalt catalysts used for auto-thermal reforming [8], carbon monoxide methanation [9] and CO hydrogenation [2], etc.

Literature studies showed several synthesis methods for hydrotalcite based catalyst. The mostly used method is the co-precipitation [10] at different $\mathrm{pH}$ and temperatures. A hydrothermal method at high temperature is also reported as another technique of synthesis of hydrotalcite [11]. The reported reaction time for this method is too long from 7-42 days. Another alternative method for the synthesis of hydrotalcite is the urea method based on the precipitation by hydrolysis of urea [12]. Recently, the HTs, like Ni and Co-Ni, were synthesized by coprecipitation method $[13,14]$.

Attempts were made to use hydrotalcites as support material for catalysts used in FTS reactions. Those studies suggest that the hydrotalcite based cobalt catalyst showed higher activity for Fisher-Tropsch synthesis applications due to the higher relative surface areas and higher reducibility [2]. Beside this, some studies also focused on the effect of change of aluminium and magnesium molar ratio in hydrotalcite and suggested that lower $\mathrm{Mg} / \mathrm{Al}$ leads to improved dispersion of cobalt in the crystal [15]. Recent studies showed that hydrothermal process could significantly enhance the catalyst FTS activity and $\mathrm{C}_{5+}$ selectivity [16].
The main focus of this study is to synthesize hydrotalcite supported cobalt catalyst for FTS by using two different synthesis methods. Coprecipitation and hydrothermal are two main techniques used for the synthesis of the catalyst. The prepared catalysts were characterized using various techniques and then tested for FTS in a fixed bed micro reactor.

\section{Experimentation}

\subsection{Catalyst preparation}

Two different techniques, co-precipitation method, and hydrothermal method were used for the synthesis of catalyst.

\subsubsection{Co-precipitation method (HT-Co-CPPT)}

HT-Co-CPPT catalyst was prepared with 40 wt $\%$ cobalt metal loading. Metal nitrate solutions were prepared by adding magnesium nitrate hexahydrate $\left(\mathrm{Mg}\left(\mathrm{NO}_{3}\right)_{2} .6 \mathrm{H}_{2} \mathrm{O}=8.01 \mathrm{~g}\right)$, aluminium nitrate nonahydrate $\left(\mathrm{Al}\left(\mathrm{NO}_{3}\right)_{3} .9 \mathrm{H}_{2} \mathrm{O}=7.03 \mathrm{~g}\right)$, and cobalt nitrate $\left(\mathrm{Co}\left(\mathrm{NO}_{3}\right)_{2} .6 \mathrm{H}_{2} \mathrm{O}=7.27 \mathrm{~g}\right)$ in $100 \mathrm{~mL}$ deionizes water. Ten hundred $\mathrm{mL}$ solutions of sodium carbonate $\left(\mathrm{Na}_{2} \mathrm{CO}_{3}\right)(1.49 \mathrm{~g})$ and sodium hydroxide $(\mathrm{NaOH})(8.99 \mathrm{~g})$ were used as the precipitating agent. The metal solutions and precipitating agents were mixed at a rate of 60-70 drops per minute along with constant stirring. The $\mathrm{pH}$ of the solution around 8-9 was maintained by the addition of concentrated nitric acid $\left(\mathrm{HNO}_{3}\right)$ The solution was then heated at $80{ }^{\circ} \mathrm{C}$ for 18 hours with constant stirring to complete the precipitation followed by filtration, washing, and drying overnight at $85{ }^{\circ} \mathrm{C}$ and calcinations at $600^{\circ} \mathrm{C}$ for $7 \mathrm{~h}$.

\subsubsection{Hydrothermal method (HT-Co-HT)}

HT-Co-HT catalyst with 40 wt\% Co metal loading was prepared by hydrothermal method. The precipitating agent and metal nitrate solutions were prepared as described in the above section. After mixing and $\mathrm{pH}$ adjustment, the solution was heated around $100{ }^{\circ} \mathrm{C}$ in a hydrothermal autoclave for $8 \mathrm{~h}$. The precipitates were then separated, extensively washed with deionized water, dried at $80^{\circ} \mathrm{C}$ overnight in an oven and calcined at $600{ }^{\circ} \mathrm{C}$ for $7 \mathrm{~h}$.

\subsection{Catalyst characterization}

The surface morphology and elemental composition of the prepared samples were determined by Scanning Electron Microscope (SEM modal JEOL, JED 2300 equipped with EDX Thermal Gravimetric Analysis (TGA) with 
Mettler TGA/SDTA 851eX-ray diffraction spectroscopy (XRD) with Bruker D8 System operating at $40 \mathrm{kV}$ and $30 \mathrm{~mA}$, step size 0.01 , scan angle $10^{\circ}$ to $80^{\circ}$ and 0.2 sec per scan, and Fourier Transform Infrared Spectroscopy (FTIR) with Perkin Elmer Spectrum 100 Spectrometer.

\subsection{Catalyst testing}

The testing unit for Fischer-Tropsch synthesis is shown in Figure 1. Fischer-Tropsch catalytic activity was tested in a fixed bed microreactor having a length of $10 \mathrm{~cm}$ with a diameter of $3.3 \mathrm{~cm}$. One $\mathrm{g}$ of freshly prepared catalyst was loaded into the reactor along with $5 \mathrm{~g}$ of ceramic balls as diluting material $[17,18]$. The inert ceramic balls having no effect on the activity and selectivity of the catalyst; were used for increasing the surface area of the catalyst. The loaded catalyst was initially reduced at $400{ }^{\circ} \mathrm{C}$ for $16 \mathrm{~h}$ using hydrogen gas at a flow rate of 50 $\mathrm{sccm}$. The reaction was carried out at $250{ }^{\circ} \mathrm{C}$ with hydrogen to carbon monoxide ratio of $2: 1$ $[18,19]$. Flow rates were maintained at $50 \mathrm{sccm}$ of hydrogen, $25 \mathrm{sccm}$ of carbon monoxide and $10 \mathrm{sccm}$ of nitrogen. The pressure of the reactor was maintained at 20 bars $(0.20 \mathrm{MPa})$. The product was collected in the separator 1 (Hot Trap) at $150{ }^{\circ} \mathrm{C}$ and Separator 2 (Cold Trap) at room temperature. The 'Shimadzu QP2010 Ultra' system is used for GC-MS analysis of prod- uct obtained from both separators. Injection temperature was set at $120{ }^{\circ} \mathrm{C}$. Helium was used as carrier gas at a pressure of $89.3 \mathrm{KPa}$ and column flow rate of $1.44 \mathrm{~mL} / \mathrm{min}$. The total flow was $158.9 \mathrm{~mL} / \mathrm{min}$ and total time of the process is 25 mins. The peak area in GCMS results is used to calculate the product selectivity.

\section{Results and Discussion}

\subsection{Catalyst characterization}

\subsubsection{Characterization by X-Ray Diffraction}

The $\mathrm{x}$-ray diffraction pattern of both catalysts prepared through co-precipitation and hydrothermal methods are shown in Figure 2. A hexagonal closed packed (hcp) ferromagnetic structure was observed for cobalt, whereas, at high pressures when the magnetism is adequately suppressed, we observe a transference from hexagonal closed packed (hcp) to cubic face centered structure (fcc) [20]. Figure 2 shows peaks at $31^{\circ}, 37^{\circ}, 44.8^{\circ}, 65^{\circ}$ represents a cubic crystalline form of cobalt oxide $\left(\mathrm{Co}_{3} \mathrm{O}_{4}\right)$ $[21,22]$. The $\mathrm{Co}^{2+}$ ion has slightly larger ion radius than the $\mathrm{Al}^{3+}$ and $\mathrm{Mg}^{2+}$ (having ion radius of $60 \mathrm{pm}$ and $65 \mathrm{pm}$, respectively) hence the insertion of big cobalt ions in the hydrotalcite structure renders the structure less crystalline [23].

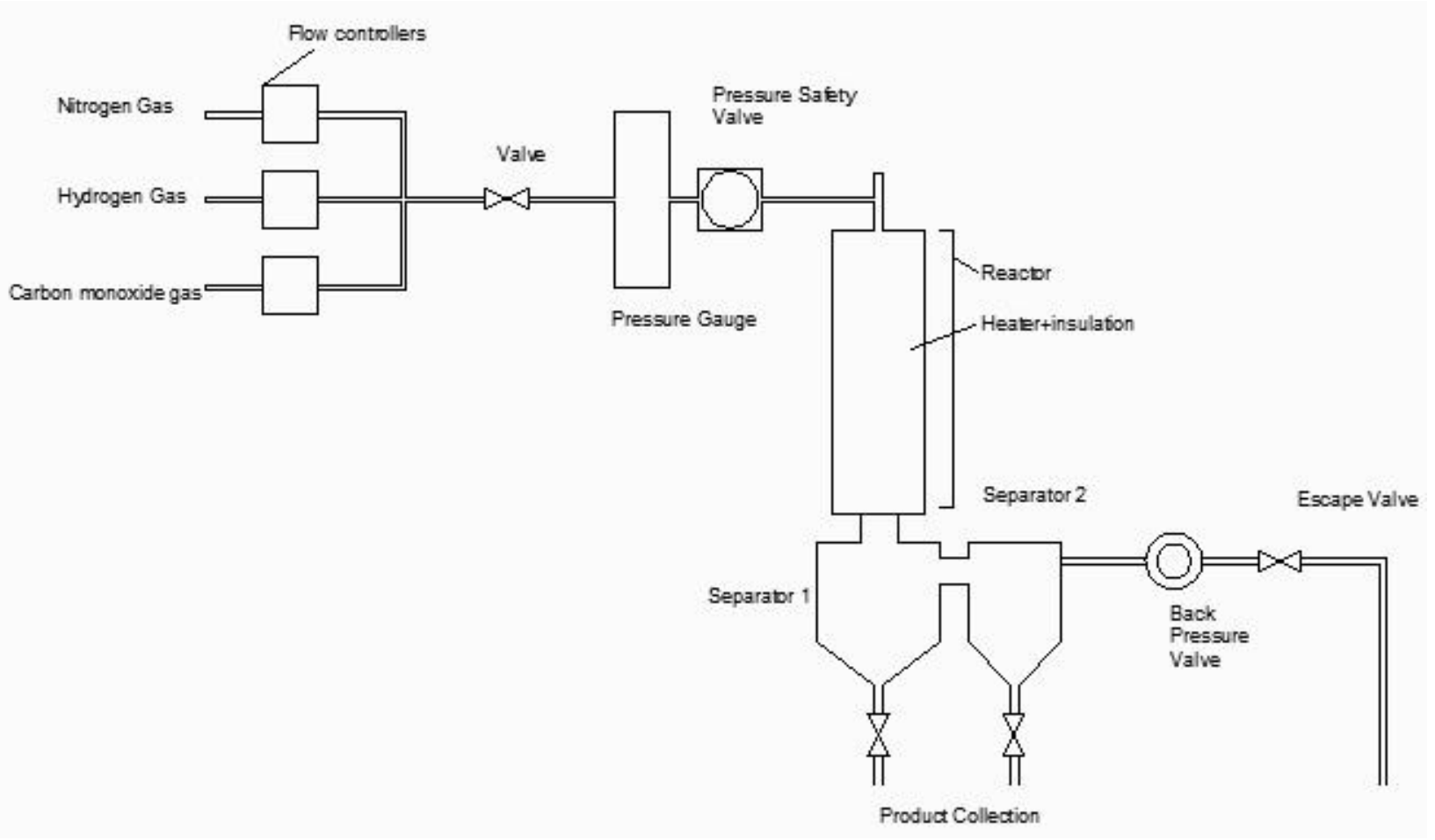

Figure 2. FTS plant diagram 


\subsubsection{Characterization by SEM}

SEM micrographs of the calcined samples are shown in Figure 3. SEM images show the development of irregular shaped rock-like aggregates of diverse sizes with small platy particles. Most of the particles in the lattice have a size of few micrometers ranging from 1-10 $\mu \mathrm{m}$. However, some aggregates have a size exceeding $10 \mu \mathrm{m}$. Elemental analysis of the catalysts prepared by both methods is shown in Table 1 . 32 to $36 \%$ cobalt loading was confirmed by



Figure 2. XRD patterns of calcined samples of (1) HT-Co-CPPT, (2) HT-Co-HT


EDX analysis. Samples prepared by co precipitation method showed less cobalt loading of 32 $\%$ while samples prepared by hydrothermal method showed higher cobalt loading of $36 \%$. The change in the oxygen percentage is a proof of other oxygenates formed in both of the synthesis methods.

\subsubsection{Characterization by TGA}

Thermal gravimetric analysis of calcined samples are performed in nitrogen atmosphere

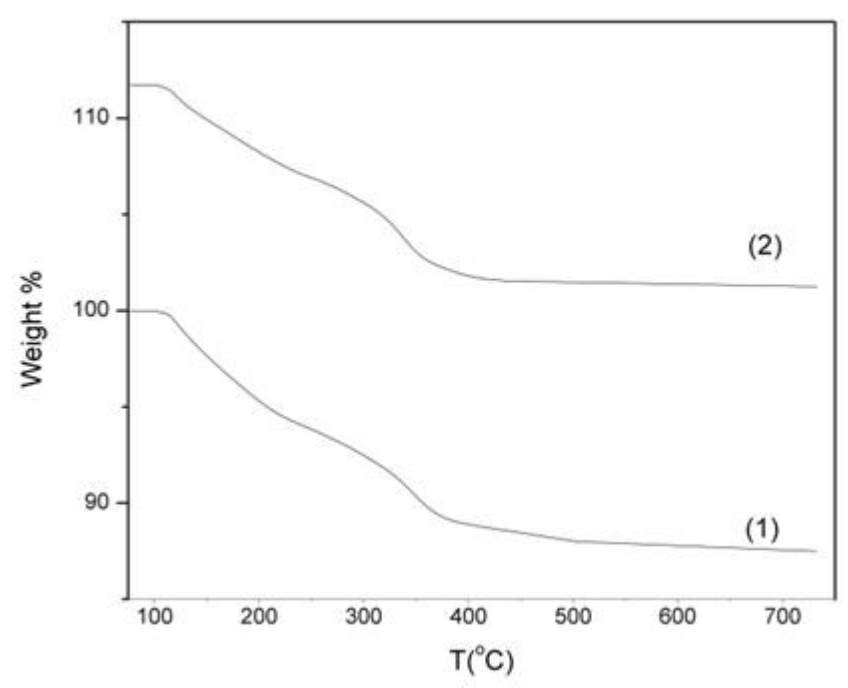

Figure 4. Thermal gravimetric analysis of (1) HT-Co-CPPT, (2) HT-Co-HT

Figure 3. SEM micrographs of HT-Co catalyst after calcination: (a) HT-Co-CPPT at X5000, (b) HT-CoCPPT at X500, (c) HT-Co-HT at X5000, (d) HT-Co-HT at X500 
are shown in Figure 4. The hydrotalcite material usually has two characteristic weight loss. The first weight loss occurs from 110 to $280{ }^{\circ} \mathrm{C}$ is due to the elimination of water of hydration from the interlayer space of the crystal. Another weight loss occurs around 280 to $370{ }^{\circ} \mathrm{C}$. The second weight loss is mainly because of elimination of hydroxyl group $(\mathrm{OH})$ from inlaid water molecules $[24,25]$.

\subsubsection{Surface Area Characterization by BET}

Nitrogen physisorption measurements were performed using Tristar II 3020 apparatus. The samples were outgassed under vacuum at 300 ${ }^{\circ} \mathrm{C}$ for 5 hours. Table 2 shows the surface area, pore volume, pore size and particle size of prepared catalyst. Greater surface area of 87.84 $\mathrm{m}^{2} / \mathrm{g}$ for the samples prepared by hydrothermal method as compared to $37.88 \mathrm{~m}^{2} / \mathrm{g}$ in case of coprecipitation method confirm the advantage of hydrothermal method over co-precipitation method. The average particle size was calculated from BET analysis by BJH method. The hydrothermal method leads to supercritical conditions which result in small particle size and larger pore volume which give higher surface area as compared to co-precipitation method [26]. The smaller average particle size and larger pore volume of the samples prepared by hydrothermal method also confirm advantages of this process [27,28].

\subsubsection{Characterization by FTIR}

Figure 5 shows the FTIR spectra of the two samples. It is evident from the spectra that there exists a trough around $3400 \mathrm{~cm}^{-1}$ in case of HT-Co-CPPT and $3700 \mathrm{~cm}^{-1}$ in case of HTCo-HT, correspond to the $-\mathrm{OH}$ stretching between $2500 \mathrm{~cm}^{-1}$ and $3900 \mathrm{~cm}^{-1}$ [29]. The ab- sorption at $1650 \mathrm{~cm}^{-1}$ corresponds to $\mathrm{H}-\mathrm{OH}$ bending vibration. The $\mathrm{Co}-\mathrm{O}$ stretching for the characteristic absorption of $\mathrm{Co}_{3} \mathrm{O}_{4}$ spinal phase at $668 \mathrm{~cm}^{-1}$ is evident from the spectra [3]. The peak around $550 \mathrm{~cm}^{-1}$ represents the $\mathrm{Al}_{2} \mathrm{O}_{3}$ stretching [20]. The calcined material leads to the formation of wide bands attributed to the cobalt oxide phase. After calcination, the absorption band of the nitrate anion is very insignificant due to nitrate degradation.

\subsection{Catalyst testing}

Table 3 shows the catalytic activity for both of our prepared catalysts HT-Co-CPPT catalyst gave $68.45 \%$ selectivity for lighter hydrocarbons $\left(<\mathrm{C}_{5}\right)$ and $31.54 \%$ of $\mathrm{C}_{5+}$ hydrocarbons. Similarly HT-Co-HT showed selectivity of $62.52 \%$ for lighter hydrocarbons and $37.47 \%$ selectivity for $\mathrm{C}_{5+}$ hydrocarbons. Overall the catalyst prepared by hydrothermal method

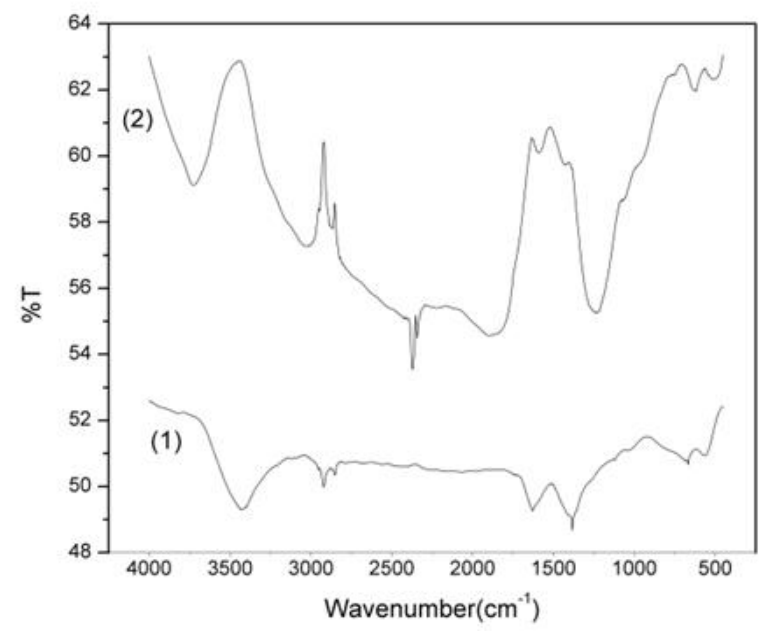

Figure 5. FTIR spectra of (1) HT-Co-CPPT, (2) HT-Co-HT

Table 1. EDS of HT-Co prepared by co-precipitation and hydrothermal method

\begin{tabular}{cccccc}
\hline \multirow{2}{*}{ Sample ID } & \multicolumn{5}{c}{ Weight Percentage \% } \\
\cline { 2 - 6 } & $\mathrm{O}$ & $\mathrm{Na}$ & $\mathrm{Mg}$ & $\mathrm{Al}$ & $\mathrm{Co}$ \\
\hline HT-Co-CPPT & 42.81 & 4.35 & 12.15 & 8.46 & 32.22 \\
HT-Co-HT & 39.64 & 3.75 & 12.34 & 8.39 & 35.89 \\
\hline
\end{tabular}

Table 2. BET analysis of calcined catalyst prepared by co-precipitation and hydrothermal method

\begin{tabular}{ccccc}
\hline Sample & $\begin{array}{c}\text { BET Surface Area } \\
\left(\mathrm{m}^{2} / \mathrm{g}\right)\end{array}$ & $\begin{array}{c}\text { Pore volume } \\
\left(\mathrm{cm}^{3} / \mathrm{g}\right)\end{array}$ & $\begin{array}{c}\text { Pore size } \\
(\mathrm{nm})\end{array}$ & $\begin{array}{c}\text { Avg. particle size } \\
(\mathrm{nm})\end{array}$ \\
\hline HT-Co-CPPT & 37.88 & 0.064 & 7.67 & 158.36 \\
HT-Co-HT & 87.84 & 0.142 & 6.61 & 68.3 \\
\hline
\end{tabular}


Table 3. FTS Product analysis obtained with catalyst HT-Co-CPPT and catalyst HT-Co-HT

\begin{tabular}{ccccc}
\hline Catalyst & $\begin{array}{c}\text { Reactor Pressure } \\
\text { (bar) }\end{array}$ & $\mathrm{H}_{2}$ to $\mathrm{CO}$ ratio & \multicolumn{2}{c}{ Selectivity (\%) } \\
\cline { 4 - 5 } HT-Co-CPPT & 20 & $2: 1$ & 68.45 & $\geq \mathrm{C}_{5}$ to $\mathrm{C}_{27}$ \\
HT-Co-HT & 20 & $2: 1$ & 62.52 & 31.54 \\
\hline
\end{tabular}

gave more selectivity towards $\mathrm{C}_{5+}$ as compared to co-precipitation method.

\section{Conclusions}

Hydrotalcite supported cobalt catalysts were synthesized using co-precipitation as well as hydrothermal techniques. The characterization reveals that HT-Co-HT has more cobalt metal loading and have more stable crystal structure as compared to HT-Co-CPPT. The hydrothermal method leads to a high surface area of catalyst as compared to co-precipitation method due to supercritical conditions. Catalyst testing for Fischer-Tropsch synthesis showed higher $\mathrm{C}_{5+}$ selectivity by catalyst prepared through hydrothermal as compared to other. Hence it is evident from the above results that hydrothermal method significantly improves crystal structure, reduction behavior, and surface area which in turns increase the catalyst activity and selectivity towards desired hydrocarbons.

\section{Acknowledgement}

The authors would like to acknowledge financial support from NUST and Fauji Fertilizer Company Limited for providing funding for FT plant for carrying out this research work.

\section{References}

[1] Fu, T., Jiang, Y., Lv, J., Li, Z. (2013). Effect of Carbon Support on Fischer-Tropsch Synthesis Activity and Product Distribution over Cobased Catalysts. Fuel Processing Technology, 110: 141-149.

[2] Tsai, Y.-T., Mo, X., Campos, A., Goodwin, J.G., Spivey, J.J. (2011). Hydrotalcite Supported Co Catalysts for CO Hydrogenation. Applied Catalysis A: General, 396: 91-100.

[3] Di Fronzo, A., Pirola, C., Comazzi, A., Galli, F., Bianchi, C., Di Michele, A., Vivani, R., Nocchetti, M., Bastianini, M., Boffito, D. (2014). Co-based Hydrotalcites as New Catalysts for the Fischer-Tropsch Synthesis Process. Fuel, 119: 62-69.

[4] Pöhlmann, F., Jess, A. (2015), Interplay of Reaction and Pore Diffusion during Cobalt-
Catalyzed Fischer-Tropsch Synthesis with $\mathrm{CO}_{2}$-Rich Syngas. Catalysis Today, 275: 172182.

[5] Dry, M.E. (2002). The Fischer-Tropsch Process: 1950-2000. Catalysis Today, 71: 227-241.

[6] Iglesia, E. (1997). Design, Synthesis, and Use of Cobalt-Based Fischer-Tropsch Synthesis Catalysts. Applied Catalysis A: General, 161: 59-78.

[7] Khodakov, A.Y., Chu, W., Fongarland, P. (2007). Advances in the Development of Novel Cobalt Fischer-Tropsch Catalysts for Synthesis of Long-Chain Hydrocarbons and Clean Fuels. Chemical Reviews, 107: 1692-1744.

[8] Takehira, K., Shishido, T., Wang, P., Kosaka, T., Takaki, K. (2004). Autothermal Reforming of $\mathrm{CH}_{4}$ over Supported Ni Catalysts Prepared from $\mathrm{Mg}-\mathrm{Al}$ Hydrotalcite-Like Anionic Clay. Journal of Catalysis, 221: 43-54.

[9] He, L., Lin, Q., Liu, Y., Huang, Y. (2014). Unique Catalysis of Ni-Al Hydrotalcite Derived Catalyst in $\mathrm{CO}_{2}$ Methanation: Cooperative Effect between $\mathrm{Ni}$ Nanoparticles and a Basic Support. Journal of Energy Chemistry, 23: 587-592.

[10] Rives, V. (2001). Layered Double Hydroxides: Present and Future, $2^{\text {nd }}$ ed., New York. Nova Science Publishers.

[11] Pausch, I., Lohse, H.H., Schtirmann, K., Alhnann, R. (1986). Syntheses of Disordered and Al-rich Hydrotalcite-Like Compounds, Clays and Clay Minerals, 34: 507-510.

[12] Costantino, U., Marmottini, F., Nocchetti, M., Vivani, R. (1998). New Synthetic Routes to Hydrotalcite-Like Compounds - Characterisation and Properties of the Obtained Materials, European Journal of Inorganic Chemistry 1439-1446

[13] Ochoa-Fernandez, E., Lacalle-Vila, C., Christensen, K., Walmsley, J.C., Holmen, M.A., Chen, D. (2007). Ni catalysts for sorption enhanced steam methane reforming, Topics in Catalysis, 45: 3-8

[14] He, L., Berntsen, H., Ochoa-Fernandez, E., Walmsley, J.C., Blekkan, E.A., Chen, D. (2009). Co-Ni Catalysts Derived from Hydrotalcite-Like Materials for Hydrogen Produc- 
tion by Ethanol Steam Reforming. Topics in Catalysis, 52(3): 206-217

[15] Forgionny, A., Fierro, J., Mondragón, F., Moreno, A. (2016). Effect of $\mathrm{Mg} / \mathrm{Al}$ Ratio on Catalytic Behavior of Fischer-Tropsch CobaltBased Catalysts Obtained from Hydrotalcites Precursors. Topics in Catalysis, 59: 230-240.

[16] Zhang, J., Lu, S., Fan, S., Zhao, T., Zhang, K. (2015). Hydrothermal Preparation of Fe-Mn Catalyst for Light Olefin Synthesis from CO Hydrogenation. Nano Reports, 1: 15-19

[17] Bianchi, C.L., Pirola, C., Ragaini, V. (2006). Choosing the Best Diluent for a Fixed Catalytic Bed: The Case of CO Hydrogenation. $\mathrm{Ca}$ talysis Communications, 7: 669-672.

[18] Ermolaev, V.S., Gryaznov, K.O., Mitberg, E.B., Mordkovich, V.Z., Tretyakov, V.F. (2015). Laboratory and Pilot Plant Fixed-Bed Reactors for Fischer-Tropsch Synthesis: Mathematical Modeling and Experimental Investigation. Chemical Engineering Science, 138: $1-8$.

[19] Irankhah, A., Haghtalab, A., Farahani, E.V., Sadaghianizadeh, K. (2007). Fischer-Tropsch Reaction Kinetics of Cobalt Catalyst in Supercritical Phase. Journal of Natural Gas Chemistry, 16: 115-120.

[20] Yoo, C.-S., Söderlind, P., Cynn, H. (1998). The Phase Diagram of Cobalt at High Pressure and Temperature: The Stability of-Cobalt and New-Cobalt. Journal of Physics: Condensed Matter. 10: L311

[21] Trépanier, M., Dalai, A.K., Abatzoglou, N. (2010). Synthesis of CNT-Supported Cobalt Nanoparticle Catalysts using a Microemulsion Technique: Role of Nanoparticle Size on Reducibility, Activity and Selectivity in Fischer-Tropsch Reactions. Applied Catalysis A: General, 374: 79-86.

[22] Tavasoli, A., Abbaslou, R.M.M., Dalai, A.K. (2008). Deactivation Behavior of Ruthenium Promoted $\mathrm{Co} / \mathrm{Y}-\mathrm{Al}_{2} \mathrm{O}_{3}$ Catalysts in FischerTropsch Synthesis. Applied Catalysis A: General, 346: 58-64.
[23] He, L., Berntsen, H., Ochoa-Fernández, E., Walmsley, J.C., Blekkan, E.A., Chen, D. (2009). Co-Ni Catalysts Derived from Hydrotalcite-Like Materials for Hydrogen Production by Ethanol Steam Reforming. Topics in Catalysis, 52: 206-217.

[24] Jiang, Z., Yu, J., Cheng, J., Xiao, T., Jones, M.O., Hao, Z., Edwards, P.P. (2010). Catalytic Combustion of Methane over Mixed Oxides Derived from Co-Mg/Al Ternary Hydrotalcites. Fuel Processing Technology, 91: 97-102.

[25] Perez-Ramirez, J., Mul, G., Kapteijn, F., Moulijn, J. (2001). A Spectroscopic Study of the Effect of the Trivalent Cation on the Thermal Decomposition Behaviour of Cobased Hydrotalcites. Journal of Materials Chemistry, 11: 2529-2536.

[26] Hiromichi, H., Yukiya, H. (2010). Hydrothermal Synthesis of Metal Oxide Nanoparticles in Supercritical Water, Materials, 3: 37943817

[27] Tantirungrotechai, J., Chotmongkolsap, P., Pohmakotr, M. (2010). Synthesis, Characterization, and Activity in Transesterification of Mesoporous Mg-Al Mixed-Metal Oxides. Microporous and Mesoporous Materials, 128: 4147.

[28] Bastiani, R., Zonno, I., Santos, I., Henriques, C., Monteiro, J. (2004). Influence of Thermal Treatments on the Basic and Catalytic Properties of $\mathrm{Mg}$, Al-mixed Oxides Derived from Hydrotalcites. Brazilian Journal of Chemical Engineering, 21: 193-202.

[29] Kloprogge, J.T., Frost, R.L. (1999). Fourier Transform Infrared and Raman Spectroscopic Study of the Local Structure of $\mathrm{Mg}$-, Ni-, and Co-hydrotalcites. Journal of Solid State Chemistry, 146: 506-515. 